\title{
Anatomical characteristics and significance of the metopism and Wormian bones in dry adult-Chinese skulls
}

\author{
J.-H. Li ${ }^{1 *}$ (D), Z.-J. Chen ${ }^{1 *}$, W.-X. Zhong ${ }^{1 *}$, H. Yang ${ }^{1}$, D. Liu' ${ }^{1,2}$, Y.-K. Li ${ }^{1}$ \\ 'School of Traditional Chinese Medicine, Southern Medical University, Guangzhou, Guangdong, P.R. China \\ 2Department of Rehabilitation Medicine, the Third Affiliated Hospital, Southern Medical University, Guangzhou, \\ Guangdong, P.R. China
}

[Received: 28 October 2021; Accepted: 29 December 2021; Early publication date: 21 January 2022]

\begin{abstract}
Background: This study aimed to investigate the incidence, topographical distribution, morphology, and interrelationship of the metopism and Wormian bones (WBs) in dry adult-Chinese skulls.

Materials and methods: In this study, 285 dried adult-Chinese skull specimens from the Department of Anatomy at the Southern Medical University were examined. The incidence of different types of metopism and WBs were recorded. The length of the metopic suture was measured using a flexible ruler. Additionally, the lengths and widths of the WBs were measured using a vernier calliper.

Results: The incidence of metopism and WBs in Chinese adults were estimated at $10.18 \%$ (29/285) and 63.86\% (182/285), respectively. The metopism always accompanied WBs $(26 / 29,89.66 \%)$, but the WBs did not necessarily accompany metopism (26/182, 14.29\%). The locations of the WBs in the order of decreasing incidence were the lambdoid suture $(78.57 \%, 143 / 182)$, pterion $(34.62 \%, 63 / 182)$, asterion $(12.09 \%, 22 / 182)$, lambda $(8.24 \%, 15 / 182)$, sagittal suture $(4.95 \%$, 9/182), and Inca bone (3.85\%, 7/182). These locations differed in topographical distribution and morphological patterns.

Conclusions: Chinese adults differ in incidence of metopism and WBs from adults of other races, indicating racial differences. The characteristics of WBs vary depending on the cranial site of occurrence. The metopism always accompanies WBs, but the WBs do not necessarily accompany metopism. (Folia Morphol 2023; 82, 1: 166-175)
\end{abstract}

Key words: Chinese, skull, metopic suture, metopism, Wormian bones, anatomical characteristics

\section{INTRODUCTION}

The skull is the most complex skeletal structure in the human body. The skull of a young adult consists of 28 separate flat and irregular bones, most of which are connected by "cranial sutures" [39]. The metopic suture (MS) is an important cranial suture connecting the bregma to the nasion in the cranial vault. It presumably helps the fetus pass smoothly through the birth canal and assists in brain development, along with the coronal, sagittal, and lambdoid sutures $[7,16]$.

Address for correspondence: Dr. Y.-K. Li, School of Traditional Chinese Medicine, Southern Medical University, No. 1838, North of Guangzhou Great Road, BaiYun District, Guangzhou, Guangdong Province, 510515, China, e-mail: ortho@smu.edu.cn 
Closure of the MS typically occurs in infancy or early childhood, but the exact timing is controversial. Most researchers believe that this process is completed by the age of 7 years [40-42]. Incomplete closure of the MS leads to a persistent metopic suture (also known as the metopism or median frontal suture) in adults $[3,26,44]$. Metopism is usually considered a normal anatomical variant, but several researchers believe it is associated with clinically significant findings $[41,44]$.

Wormian bones (WBs, also known as the isolated sutural bones or supernumerary bones) are irregularly shaped bones formed from additional ossification centres and almost always located in or near the cranial sutures and fontanelles $[9,27]$. The isolated bone at the lambda is often referred to as Goethe's ossicle, or the Inca bone due to its prevalence in the skulls of the Incas (South American Indians) [39]. These WBs are present as one or more pterion ossicles or epipteric bones in the pterion and as os Kerckring in bregma [8]. As with metopism, WBs have pathological and diagnostic implications, and their incidence varies among different populations [27]. WBs distinguished normal variation or pathology from its number, arrangement pattern, and size as important factors [17, 22].

Although metopism and WBs have been reported in various ethnic populations, few related large-scale studies on Chinese adults have been performed. Therefore, this study aimed to investigate the incidence, number, morphology, and topographical distribution of the metopism and WBs and the interrelationships among these characteristics in Chinese adults.

\section{MATERIALS AND METHODS}

\section{Materials}

For this study, 285 dried skull specimens of Chinese adults with unknown age and sex were obtained from the Department of Anatomy of the Southern Medical University in China (the exclusion criteria were damaged skulls, such as those with trauma or pathology affecting the measurement parameters, and skulls of children). All the specimens were from cadaver donations, and written informed consent had been obtained from the donors. To precisely identify the cranial sutures and assess their structural integrity, all the skull specimens were cleaned and dried.

\section{Methods}

Firstly, we assessed the incidence, number, and shape of the metopism and WBs in the specimens.
Metopism can be partial (incomplete) or complete. The partial type extends upward from the nasion or downward from the bregma; the complete type connects the bregma to the nasion [44]. Following a previously described method, only the small bones surrounded by the suture were recorded as WBs [27]. Then, the length of the metopic suture was measured (accuracy $\pm 0.1 \mathrm{~mm}$ ) using a soft ruler (Martin measure instrument). The lengths and widths of the WBs were measured using a digital vernier calliper (accuracy $\pm 0.01 \mathrm{~mm}$ ) (Wuxi Kaibaoding Tool Co., Ltd., China).

The above measurements were independently performed by 2 researchers, each researcher taking 3 measurements ( 6 measurements in total) per parameter to calculate the mean \pm standard deviation (SD). The researchers who performed the measurements had $>2$ years of experience in measurements and were uniformly trained to reduce systematic errors. Digital image acquisition (D610 type camera, Nikon) and processing (Photoshop 2020; Adobe Illustrator 2020, Adobe) were performed after the measurements were completed.

All the methods in this study followed the guidelines of the Helsinki Declaration. Ethical approval for this study was obtained from the Chinese Ethics Committee of Registering Clinical Trials (Reference number: ChiECRCT20210191).

\section{Statistical analysis}

The IBM SPSS Statistics 26.0 software for Windows was used to perform statistical analyses. The measurements were expressed as mean $\pm S D(x \pm s)$. The normality of the data was assessed using the Kolmogorov-Smirnov test. The paired samples t-test or Wilcoxon signed-rank test was used to determine whether the length and width of the bone were consistent. Statistical significance was determined by $p<0.05$ for all the analyses.

Inter- and intra-observer reliability was determined by calculating the intra-class correlation coefficient (ICC) with a confidence interval (CI) of $95 \%$. ICC $\leq 0.4$, $0.41 \leq \mathrm{ICC} \leq 0.60,0.61 \leq \mathrm{ICC} \leq 0.80$, and $0.81 \leq \mathrm{ICC}<1$ were considered to indicate poor, moderate, good, and very good agreement among the measurements, respectively. The ICC value of 1 indicates perfect reliability [43]. The ICCs of all the measurements were $>0.90$, indicating very good inter- and intra-observer agreement.

\section{Consent to participate}

All the methods in the study were carried out following the Helsinki guidelines and declaration. 
Table 1. Incidence of metopism in different ethnic groups (in descending order of incidence)

\begin{tabular}{|c|c|c|c|c|c|}
\hline No. & Author(s) & Year & Population & Specimen number (n) & Incidence (\%) \\
\hline \multirow[t]{4}{*}{1} & Zdilla et al. [44] & 2018 & East Asian & 13 & $15.38 \%$ \\
\hline & & & European & 62 & $8.06 \%$ \\
\hline & & & Bengali & 35 & $2.86 \%$ \\
\hline & & & Egyptian & 91 & $2.20 \%$ \\
\hline 2 & Present study & 2021 & Chinese & 285 & $10.18 \%$ \\
\hline \multirow[t]{14}{*}{3} & Brothwell [11] & 1981 & Iron Age Romano-British & NA & $9.91 \%$ \\
\hline & & & London $\left(17^{\text {th }} \mathrm{C}.\right)$ & NA & $9.09 \%$ \\
\hline & & & Lachish & NA & $8.81 \%$ \\
\hline & & & German & NA & $8.37 \%$ \\
\hline & & & Anglo-Saxon & NA & $8.30 \%$ \\
\hline & & & Chinese & NA & $8.17 \%$ \\
\hline & & & Ancient Egyptian & NA & $3.87 \%$ \\
\hline & & & Peruvian & NA & $2.56 \%$ \\
\hline & & & Melanesian & NA & $2.02 \%$ \\
\hline & & & N. American Indian & NA & $1.45 \%$ \\
\hline & & & Polynesian & NA & $1.33 \%$ \\
\hline & & & African Negro & NA & $1.23 \%$ \\
\hline & & & Australian & NA & $0.63 \%$ \\
\hline & & & Eskimo & NA & $0.28 \%$ \\
\hline 4 & Bilgin et al. [10] & 2013 & NA & 631 & $9.7 \%$ \\
\hline 5 & Çalışkan et al. [13] & 2018 & Turkish & 185 & $8.1 \%$ \\
\hline 6 & Cirpan et al. [14] & 2016 & Turkish & 160 & $7.5 \%$ \\
\hline 7 & Aksu et al. [4] & 2014 & West Anatolian & 160 & $7.5 \%$ \\
\hline 8 & Guerram et al. [20] & 2014 & European & 143 & $4.41 \%$ \\
\hline 9 & Ajmani et al. [3] & 1983 & Nigerian & 206 & $3.4 \%$ \\
\hline 10 & Agarwal et al. [1] & 1979 & Indian & 1276 & $2.66 \%$ \\
\hline 11 & Baaten et al. [5] & 2003 & Lebanese & NA & $1.75 \%$ \\
\hline 12 & Murlimanju et al. [26] & 2011 & Indian & 81 & $1.2 \%$ \\
\hline
\end{tabular}

NA - not available

Ethical approval for this study was obtained from the Chinese Ethics Committee of Registering Clinical Trials (Reference number: ChiECRCT20210191).

\section{RESULTS}

The incidence and characteristics of the metopism

Among all the specimens, 29 metopism cases were detected, corresponding to $10.18 \%$ (29/285) incidence, which differs from the incidence in other ethnic populations (Table 1) $[1,3-5,10,11,13,14,20,26$, 44]. Of them, 27 and 2 cases were the complete and partial types (downward from the bregma), respectively. The mean length of the complete type was $12.13 \pm 0.62$ $\mathrm{cm}$ (range: $11.25-13.34 \mathrm{~cm}$ ), and the partial type was $9.3 \mathrm{~cm}$ long on average $(8.72$ and $9.88 \mathrm{~cm}$ ) (Fig. 1).

\section{The incidence of WBs}

Among the specimens, 182 had WBs, corresponding to $63.86 \%(182 / 285)$ incidence, which differs from the incidence in other ethnic populations (Table 2) $[8,11,14,15,18,23,27,32]$. The locations of the WBs in the order of decreasing prevalence were as follows: the lambdoid suture $(78.57 \%, 143 / 182)$, pterion (34.62\%, 63/182), asterion (12.09\%, 22/182), lambda $(8.24 \%, 15 / 182)$, sagittal suture $(4.95 \%, 9 / 182)$, and Inca bone (3.85\%, 7/182).

The characteristics of the WBs in lambdoid, sagittal, and coronal sutures

The WBs in the lambdoid sutures showed unilateral distribution in 51 (35.66\%) cases and bilateral 

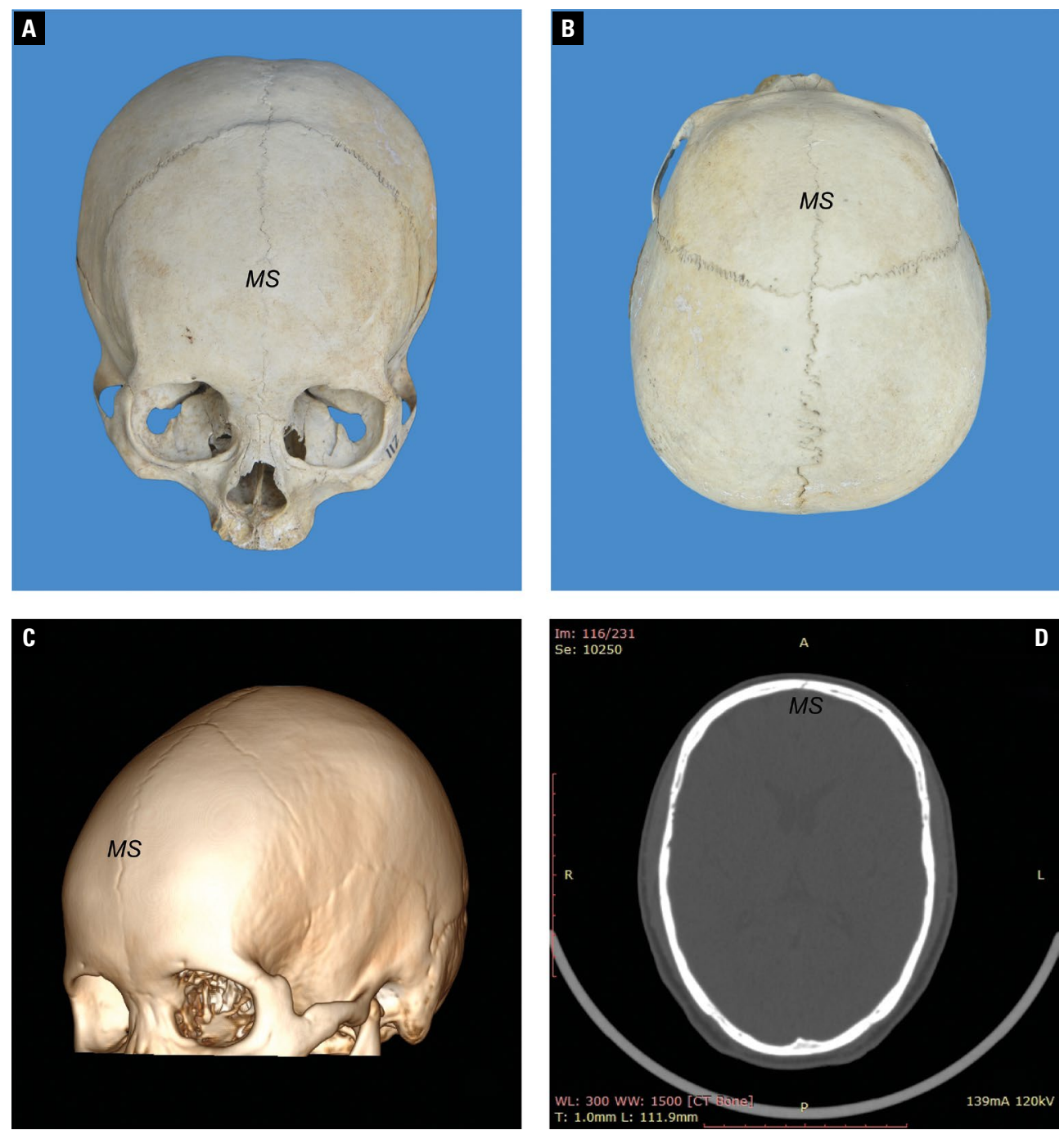

Figure 1. The anterior, superior, lateral, and cross-sectional views of the metopic suture (MS) (or metopism); A. Anterior view; B. Superior view; C. Three-dimensional visualisation of metopism via computer tomography (CT) (RadiAnt DICOM Viewer for windows); D. Metopism in a cranial CT cross-section.

in $92(64.34 \%)$ cases. Of the lambdoid-suture WB cases, 29 had only 1 WB, 105 cases had 2-10 WBs, and 9 cases had $>10$ WBs. There was no statistically significant difference in the number of WBs at the lateral level (right: $2.05 \pm 2.24$; left: $2.22 \pm 2.17$; $p>0.05)$. The majority of the WBs were parallel-fingered (with tentacles) (48.17\%), elliptical (without tentacles) $(24.08 \%)$, or single-fingered (with tentacles) $(17.8 \%)$; the remaining minority was polygonal, round, triangular, or in another shape. The mean length and width of these bones were $1.37 \pm 0.54 \mathrm{~cm}$ (range: $0.27-3.11 \mathrm{~cm}$ ) and $0.79 \pm 0.63 \mathrm{~cm}$ (range: $0.15-6.23 \mathrm{~cm}$ ), respectively; the mean length was significantly greater than the mean width $(p<0.001)$.

We also detected 9 cases of WBs in the sagittal suture, which were located in the pars obelica and pars lambdica of the suture. They were quadrilateral (44.44\%), oval (33.33\%), or finger-shaped (22.23\%). The mean length and width of these WBs were $1.70 \pm 0.30 \mathrm{~cm}$ (range: $1.35-1.91 \mathrm{~cm}$ ) and $1.46 \pm$ $\pm 0.79 \mathrm{~cm}$ (range: $0.6-2.15 \mathrm{~cm}$ ), respectively; there was no statistical significance between the mean length and width. No WB was detected in the coronal suture (Fig. 2).

The characteristics of the WBs at the pterion and asterion

Of the cases with WBs around the pterion, 37 (58.73\%) and 26 (41.27\%) had unilaterally and bilaterally distributed WBs relative to the pterion, respectively. Of the bilateral cases, 20 were symmetrical in number and position. Most of the pterion WBs were 
Table 2. Incidence of Wormian bones in different ethnic groups (In descending order of incidence)

\begin{tabular}{|c|c|c|c|c|c|}
\hline No. & Author(s) & Year & Population & Specimen number (n) & Incidence (\%) \\
\hline 1 & Basnet et al. [8] & 2019 & Nepalese & 70 & $88.57 \%$ \\
\hline 2 & Natsis et al. [27] & 2019 & Greek & 166 & $74.7 \%$ \\
\hline 3 & Present study & 2021 & Chinese & 285 & $63.86 \%$ \\
\hline 4 & Cirpan et al. [15] & 2015 & West Anatolian & 150 & $59.3 \%$ \\
\hline 5 & Cirpan et al. [14] & 2016 & Turkish & 160 & $59.3 \%$ \\
\hline 6 & Ghosh et al. [18] & 2017 & Eastern part of India & 120 & $45 \%$ \\
\hline 7 & Khan et al. [23] & 2011 & Malaysian & 25 & $24 \%$ \\
\hline 8 & Ratnaningrum [32] & 2020 & Indonesian & 69 & $15.9 \%$ \\
\hline \multirow[t]{14}{*}{9} & Brothwell [11] & 1981 & Chinese & NA & $80.32 \%$ \\
\hline & & & German & NA & $75 \%$ \\
\hline & & & Australian & NA & $72.58 \%$ \\
\hline & & & Iron Age Romano-British & NA & $71.03 \%$ \\
\hline & & & Melanesian & NA & $64.15 \%$ \\
\hline & & & Lachish & NA & $63.41 \%$ \\
\hline & & & Anglo-Saxon & NA & $55.56 \%$ \\
\hline & & & Ancient Egyptian & NA & $55.56 \%$ \\
\hline & & & Peruvian & NA & $51.85 \%$ \\
\hline & & & African Negro & NA & $45.05 \%$ \\
\hline & & & London $\left(17^{\text {th }} \mathrm{C}.\right)$ & NA & $36.02 \%$ \\
\hline & & & Polynesian & NA & $29.92 \%$ \\
\hline & & & N. American Indian & NA & $28.18 \%$ \\
\hline & & & Eskimo & NA & $25 \%$ \\
\hline
\end{tabular}

NA - not available

epipteric (71.74\%) (i.e. located at the intersection of the frontal, parietal, sphenoid, and temporal bones). However, some pterion WBs were around the squamosoparietal suture (13.04\%), between the sphenotemporal and squamosoparietal $(6.52 \%)$ or coronal and sphenoparietal $(4.35 \%)$ sutures, or around the sphenofrontal $(4.35 \%)$ or sphenotemporal $(2.17 \%)$ suture. The pterion WBs were mostly quadrilateral (including rectangular, square, and rhombic; 69.7\%), followed by triangular (21.2\%), polygonal $(6.06 \%)$, and circular (3.04\%). The mean length and width of the pterion WBs were $1.87 \pm 0.93 \mathrm{~cm}$ (range: $0.63-5.04 \mathrm{~cm}$ ) and $1.07 \pm 0.42 \mathrm{~cm}$ (range: $0.48-$ $-2.3 \mathrm{~cm}$ ); their mean length was significantly greater than their mean width $(p<0.001)$.

The WBs at the asterion were mostly bilateral (66.64\% vs. $33.36 \%$, bilateral vs. unilateral, respectively). WBs were often found with the lambdoid suture $(40.91 \%)$, squamosoparietal suture $(27.27 \%)$, Inca bone (22.73\%), or lambda bone (9.09\%) (Fig. 3).
The characteristics of the Inca and lambda bones

We found that the lambda and Inca bones were distributed on the posterior side of the skulls. Among the cases with Inca bones, 4 had one bone mass, and 3 had two separated bones. Most of the Inca bones were triangular $(4 / 7,57.14 \%)$, but a significant fraction was polygonal $(3 / 7,42.86 \%)$. The mean length and width of these bones were $4.99 \pm 0.57 \mathrm{~cm}$ (range: $4.5-$ $-5.8 \mathrm{~cm}$ ) and $5.77 \pm 4.46 \mathrm{~cm}$ (range: $2.7-12.4 \mathrm{~cm}$ ), respectively; there was no statistical difference between the mean length and width $(p>0.05)$.

All the lambda bones were found in the posterior fontanelle and were single bones. They were triangu$\operatorname{lar}(42.86 \%, 3 / 7)$, circular $(28.58 \%, 2 / 7)$, quadrilateral $(14.28 \%, 1 / 7)$, or irregularly shaped $(14.28 \%, 1 / 7)$. The mean length and width of these bones were $2.25 \pm 1.31 \mathrm{~cm}$ (range: $0.56-4.08 \mathrm{~cm}$ ) and $2.52 \pm$ $\pm 1.62 \mathrm{~cm}$ (range: $0.4-5.02 \mathrm{~cm}$ ), respectively; there was no statistical difference between the mean length and width $(p>0.05)$ (Fig. 4). 

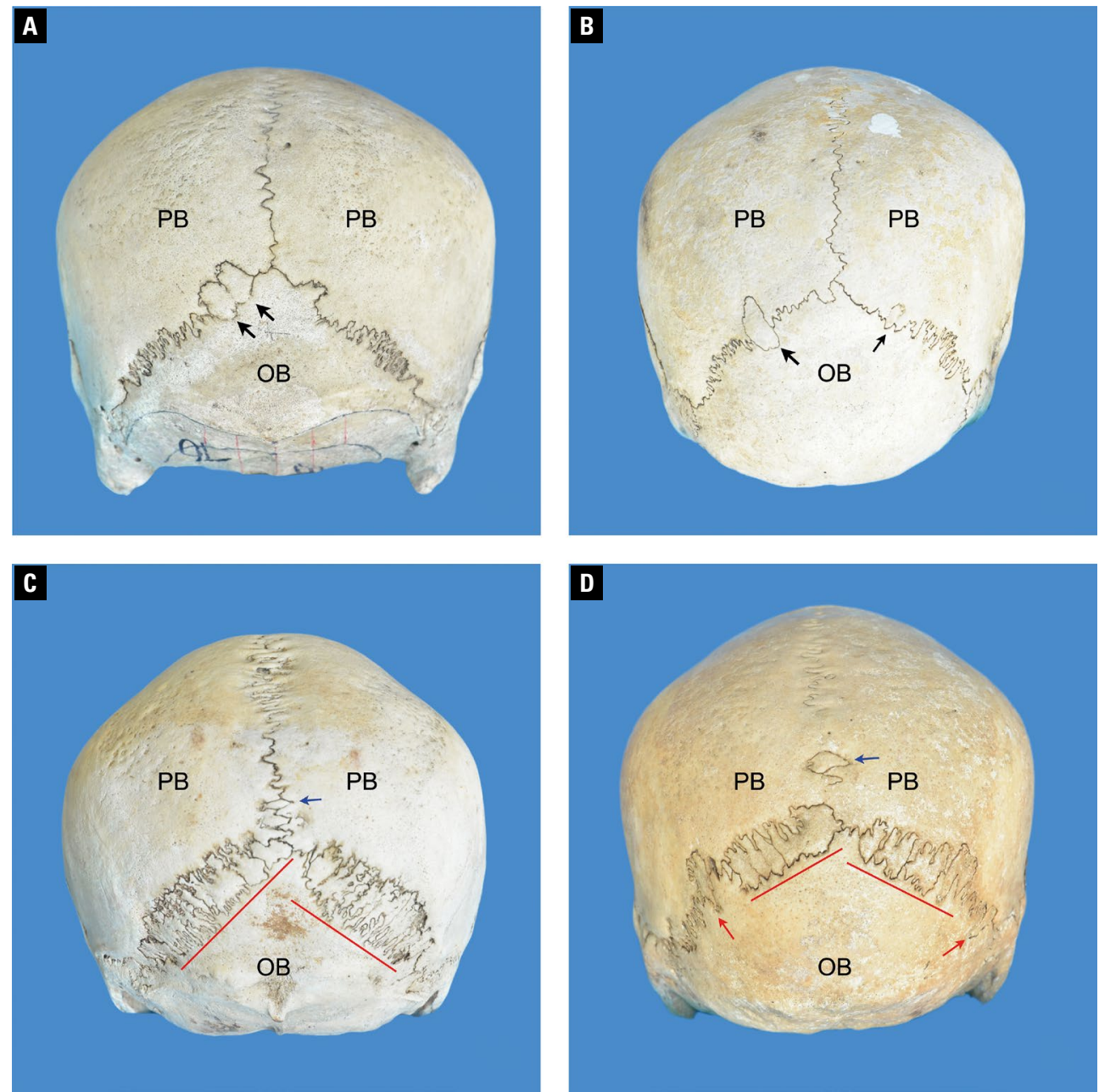

Figure 2. The Wormian bones (WBs) around the lambdoid and sagittal sutures; $\mathbf{A}$. The two WBs are located on the same side of the lambdoid suture (black arrows); B. The two WBs are symmetrically located relative to the lambdoid suture and both oval-shaped (black arrows); C, D. The complex WBs bilaterally located relative to the lambdoid suture were in a parallel-fingered (red line) shape or single-fingered with tentacles (red arrows). WBs were also found around the sagittal suture (blue arrows); PB — parietal bone; OB — occipital bone.

\section{The interrelationship between the metopism and WBs}

Among the 29 cases of metopism, 26 concurrently had WBs (89.66\%). These cases were only a sub-fraction (14.29\%) of all the cases with WBs (182 cases).

\section{DISCUSSION}

In this study, we evaluated the number, shape, and size of the WBs in different cranial locations and summarized the anatomical characteristics of these bones. The WBs in the lambdoid suture were relatively small and numerous, with a wide range of variation in morphology; most of them were narrow finger-shaped or oval-shaped. The WBs at the pterion were more prominent in size and less in number compared with other location, they were mostly regular in shape and mainly epipteric bones. Unilaterally and bilaterally distributed WBs were both observed at the lambdoid suture and pterion. However, the number of unilateral WBs at the lambdoid suture was lower than that of the bilateral ones. The bilateral WBs at the lambdoid suture was asymmetrical in number and location, whereas those at the pterion were mostly symmetrical. The WBs at the sagittal suture (lambda bone) were small in size, fixed in number and position, and mostly quadrilateral (small triangular) or oval (circular). The Inca bones were large, and primarily triangular. The WBs at the star point often concurred with WBs at other positions. The anatomical characteristics of WBs vary depending on the cranial site of occurrence.

The exact mechanism of WB formation remains unknown, and there are two major hypotheses. The first hypothesis suggests that formation of WBs is influenced by genetic factors [18]. The second hy- 

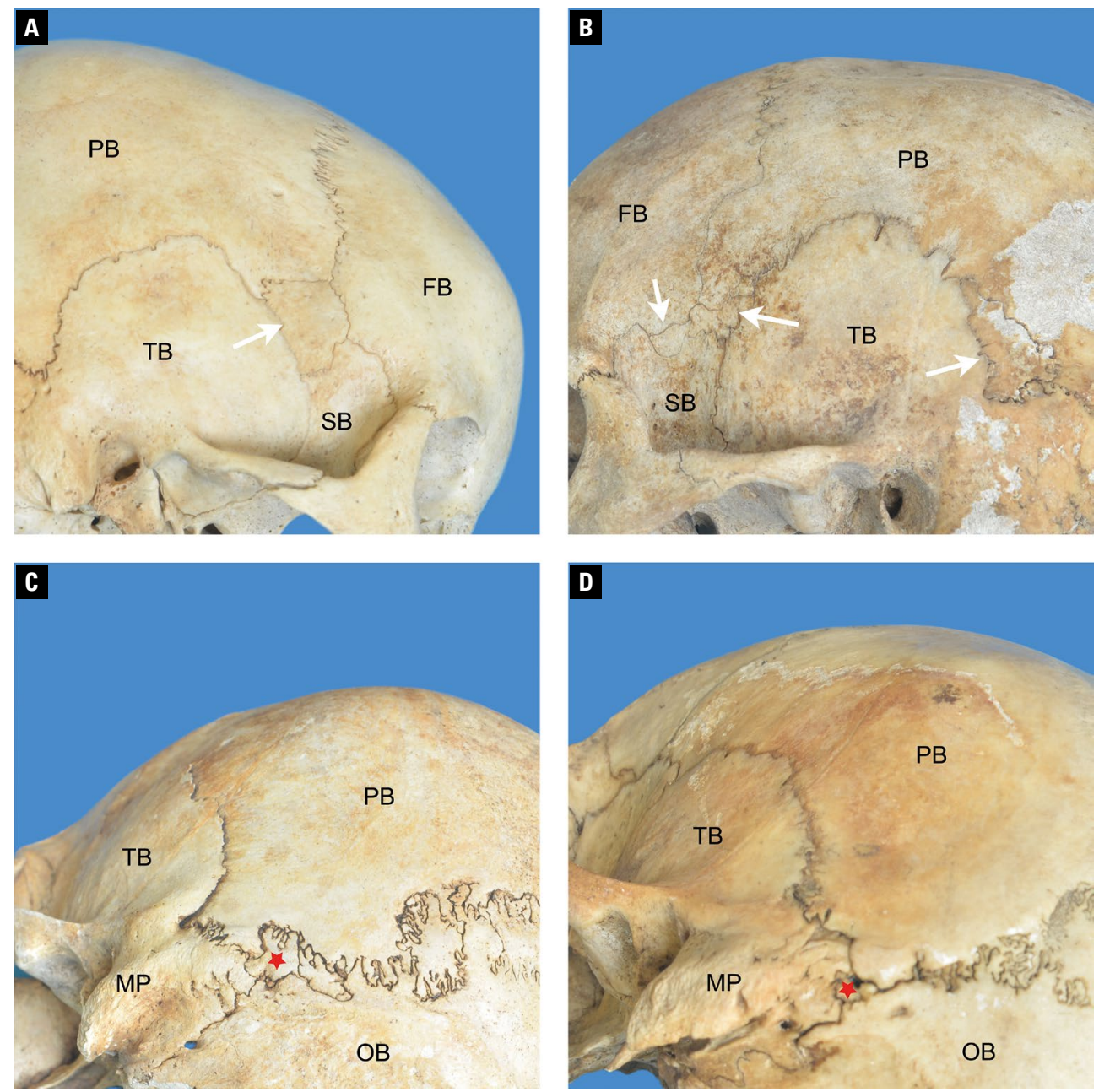

Figure 3. The Wormian bones (WBs) at the pterion and asterion; A, B. The WBs located at various locations near the pterion (white arrow); C, D. The WBs located at the asterion (red pentacle) appear together with the WBs around the lambdoid suture; FB - frontal bone; PB parietal bone; TB — temporal bone; SB — sphenoid bone; OB — occipital bone; MP — mastoid process.

pothesis suggests that environmental factors (e.g. artificial cranial deformation) cause WBs to form. The higher occurrence of WBs in the occipital region than in the frontal region may be due to environmental factors [29, 34]. However, multiple scholars believe that genetic and environmental factors influence the locations and number of WBs formed, respectively.

As a normal variant, metopism does not have any medical or morphological implications. However, multiple researchers believe that it is usually associated with malformations in the frontal region (e.g. cranium bifidum, suprasellar teratoma, cleidocranial dysostosis, hypertelorism, and facial cleft) [41]. WBs are common in adults and are also often considered a normal anatomical variant. Kozerska et al. [24] have used microcomputed tomography to examine interseptal bones and found that these bones, like other cranial bones, have both dense and cancellous bone tissues. However, occurrence of interseptal bones in children can be associated with numerous pathological conditions [27]. The presence of WBs in children is associated with developmental abnormalities in the central nervous system [31] (e.g. hydrocephalus [39], craniosynostosis [2], microcephaly, macrocephaly, cerebral palsy, epilepsy, and learning difficulties). Thus, the presence of WBs in children may serve as a marker for early diagnosis and treatment of paediatric central nervous system abnormalities. The presence of WBs can also be associated with certain types of congenital disorders (e.g. osteogenesis imperfecta $[17,36]$, Hajdu-Cheney syndrome [37], cleidocranial dysostosis [28], congenital hypothyroidism, rickets [25], limbic callosal syndrome [33] and Enlarged parietal foramina [30]).

During diagnosis or forensic identification, knowledge of metopism, WBs and craniosynostosis is es- 

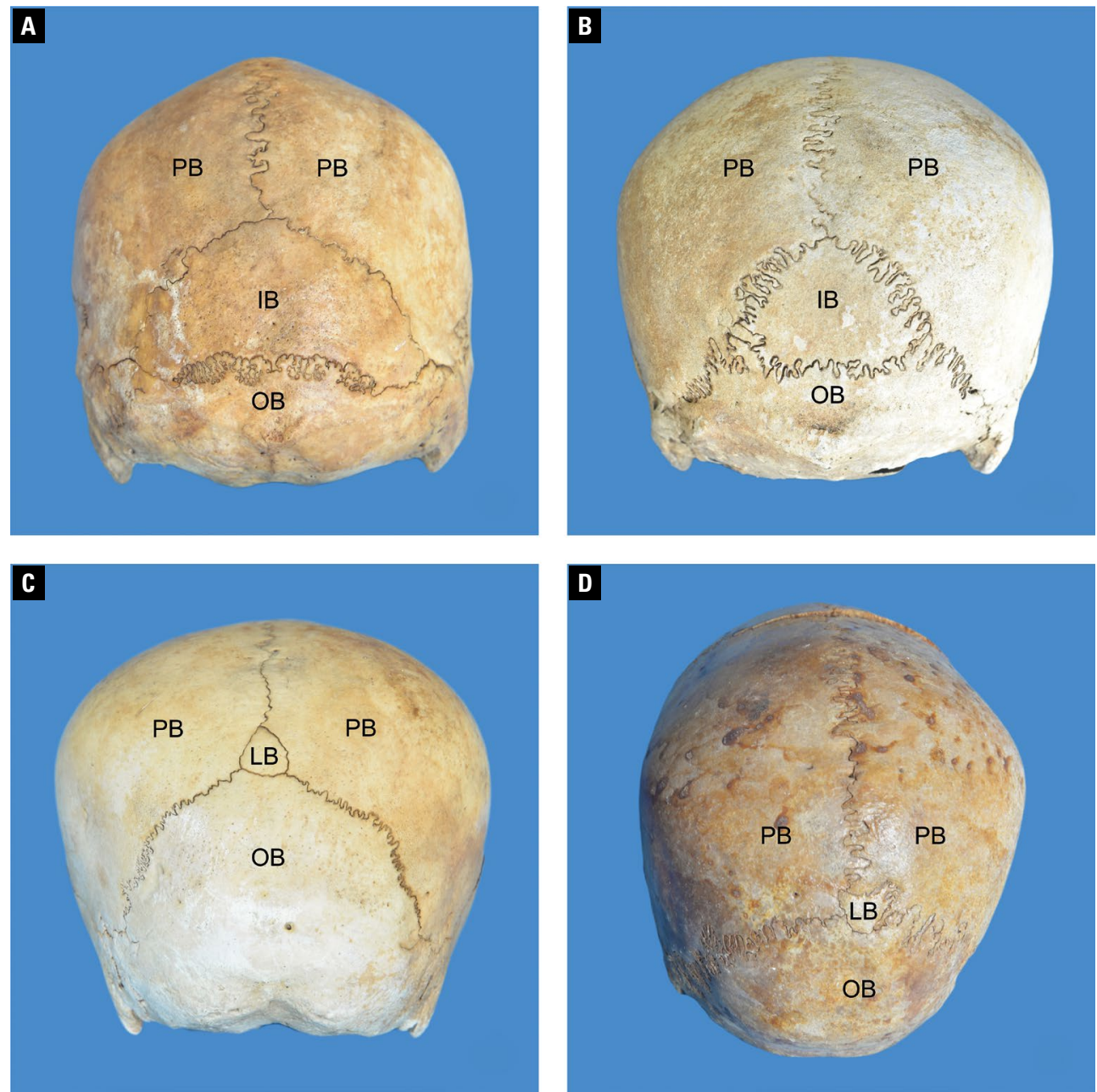

Figure 4. The Inca and lambda bones; A, B. Inca bones in the shape of large triangles; C. A lambda bone with a small triangular shape; D. An irregularly shaped lambda bone; PB — parietal bone; OB — occipital bone; IB — Inca bone; LB — lambda bone.

sential. Their presence may interfere with radiological assessment and forensic identification (easily confused with fractures or gunshot wounds) $[6,12,19$, 38]. Additionally, brain surgeons should always be cautious during a surgical operation because WBs may move and damage surrounding tissues, leading to complications [21,35].

\section{CONCLUSIONS}

Chinese adults differ in incidence of metopism and WBs from adults of other races, indicating racial differences. The characteristics of WBs vary depending on the cranial site of occurrence. The metopism always accompanies WBs, but the WBs do not necessarily accompany metopism. These results may provide an anatomical basis for teaching, clinical practice, and forensic work.

\section{Acknowledgements}

The authors are grateful to the donors for donating their bodies to science and making anatomical research possible. Results from such research can potentially increase the overall knowledge of mankind and consequently improve patient care. Therefore, these donors and their families deserve our highest gratitude.

\section{Funding}

Supported by Sanming Project of Medicine in Shenzhen (No. SZZYSM202108013); Innovation Team and Talents Cultivation Program of National Administration of Traditional Chinese Medicine. (No: ZYYCXTD-C-202003).

Conflict of interest: None declared 


\section{REFERENCES}

1. Agarwal SK, Malhotra VK, Tewari SP. Incidence of the metopic suture in adult Indian crania. Acta Anat (Basel). 1979; 105(4): 469-474, doi: 10.1159/000145154, indexed in Pubmed: 552786.

2. Agrawal D, Steinbok P, Cochrane DD. Pseudoclosure of anterior fontanelle by wormian bone in isolated sagittal craniosynostosis. Pediatr Neurosurg. 2006; 42(3): 135-137, doi: 10.1159/000091854, indexed in Pubmed: 16636612.

3. Ajmani ML, Mittal RK, Jain SP. Incidence of the metopic suture in adult Nigerian skulls. J Anat. 1983; 137 (Pt 1): 177-183, indexed in Pubmed: 6630031.

4. Aksu F, Cirpan S, Mas NG, et al. Anatomic features of metopic suture in adult dry skulls. J Craniofac Surg. 2014; 25(3): 1044-1046, doi: 10.1097/SCS.0000000000000564, indexed in Pubmed: 24699103.

5. Baaten PJJ, Haddad M, Abi-Nader K, et al. Incidence of metopism in the Lebanese population. Clin Anat. 2003; 16(2): 148-151, doi: 10.1002/ca.10050, indexed in Pubmed: 12589670.

6. Bademci G, Kendi T, Agalar F. Persistent metopic suture can mimic the skull fractures in the emergency setting? Neurocirugia (Astur). 2007; 18(3): 238-240, indexed in Pubmed: 17622463.

7. Barbeito-Andrés J, Bonfili N, Nogué JM, et al. Modeling the effect of brain growth on cranial bones using finite-element analysis and geometric morphometrics. Surg Radiol Anat. 2020; 42(7): 741-748, doi: 10.1007/s00276-02002466-y, indexed in Pubmed: 32266441.

8. Basnet LM, Shrestha S, Sapkota S. Prevalence of wormian bones in dried adult human skulls: an osteo-morphometric study in Nepal. Anat Sci Int. 2019; 94(1): 101-109, doi: 10.1007/s12565-018-0454-x, indexed in Pubmed: 30109567.

9. Bellary SS, Steinberg A, Mirzayan N, et al. Wormian bones: a review. Clin Anat. 2013; 26(8): 922-927, doi: 10.1002/ ca.22262, indexed in Pubmed: 23959948.

10. Bilgin S, Kantarcı UH, Duymus M, et al. Association between frontal sinus development and persistent metopic suture. Folia Morphol. 2013; 72(4): 306-310, doi: 10.5603/ $\mathrm{fm} .2013 .0051$, indexed in Pubmed: 24402751.

11. Brothwell DR. Digging Up Bones: The Excavation, Treatment, and Study of Human Skeletal Remains. 3rd ed. Cornell University Press, New York 1981.

12. Budinich $M$, Burgess $B$, Fisahn $C$, et al. A previously unreported variant of the synostotic sagittal suture: Case report and review of salient literature. Transl Res Anat. 2016; 5: 12-14, doi: 10.1016/j.tria.2016.12.001.

13. Çalışkan S, Oğuz KK, Tunalı S, et al. Morphology of cranial sutures and radiologic evaluation of the variations of intersutural bones. Folia Morphol. 2018; 77(4): 730-735, doi: 10.5603/FM.a2018.0030, indexed in Pubmed: 29569704.

14. Cirpan S, Aksu F, Mas N, et al. Coexistence of wormian bones with metopism, and vice versa, in adult skulls. J Craniofac Surg. 2016; 27(2): 493-495, doi: 10.1097/ SCS.0000000000002370, indexed in Pubmed: 26845093.

15. Cirpan S, Aksu F, Mas N. The incidence and topographic distribution of sutures including wormian bones in human skulls. J Craniofac Surg. 2015; 26(5): 1687-1690, doi: $10.1097 /$ SCS.0000000000001933, indexed in Pubmed: 26114515.
16. Cornelissen MJ, Söfteland M, Apon I, et al. Perinatal complications in patients with unisutural craniosynostosis: An international multicentre retrospective cohort study. J Craniomaxillofac Surg. 2017; 45(11): 1809-1814, doi: 10.1016/j. jcms.2017.08.012, indexed in Pubmed: 28935489.

17. Cremin B, Goodman H, Spranger J, et al. Wormian bones in osteogenesis imperfecta and other disorders. Skeletal Radiol. 1982; 8(1): 35-38, doi: 10.1007/BF00361366, indexed in Pubmed: 7079781.

18. Ghosh SK, Biswas S, Sharma S, et al. An anatomical study of wormian bones from the eastern part of India: is genetic influence a primary determinant of their morphogenesis? Anat Sci Int. 2017; 92(3): 373-382, doi: 10.1007/s12565016-0342-1, indexed in Pubmed: 27038026.

19. Govsa F, Ozer MA, Bayraktaroglu S, et al. Anatomoradiological identification of intrasutural bones for importance of cranial fracture. Turk Neurosurg. 2014; 24(3): 357-362, doi: 10.5137/1019-5149.JTN.8380-13.2, indexed in Pubmed: 24848174 .

20. Guerram A, Le Minor JM, Renger S, et al. Brief communication: The size of the human frontal sinuses in adults presenting complete persistence of the metopic suture. Am J Phys Anthropol. 2014; 154(4): 621-627, doi: 10.1002/ ajpa.22532, indexed in Pubmed: 24888448.

21. Guerrero Jazo FJ, Tovar Spinoza Z, Esparza Gutiérrez SV, et al. Rupture or traumatic dislocation of cranial suture on infants, involvement of the lambdoidal accessory bones (Wormian bones): case presentation and analysis. Childs Nerv Syst. 2019; 35(11): 2233-2236, doi: 10.1007/s00381019-04153-9, indexed in Pubmed: 31037423.

22. Kaplan SB, Kemp SS, Oh KS. Radiographic manifestations of congenital anomalies of the skull. Radiol Clin North Am. 1991; 29(2): 195-218, indexed in Pubmed: 1998047.

23. Khan AA, Asari MA, Hassan A. Unusual presence of Wormian (sutural) bones in human skulls. Folia Morphol. 2011; 70(4): 291-294, indexed in Pubmed: 22117248.

24. Kozerska M, Skrzat J, Walocha J, et al. Imaging of the Wormian bones using microcomputed tomography. Folia Med Cracov. 2013; 53(4): 21-28, indexed in Pubmed: 25556508.

25. Marti B, Sirinelli D, Maurin L, et al. Wormian bones in a general paediatric population. Diagn Interv Imaging. 2013; 94(4): 428-432, doi: 10.1016/j.diii.2013.01.001, indexed in Pubmed: 23352712.

26. Murlimanju BV, Prabhu LV, Pai MM, et al. Median frontal sutures - incidence, morphology and their surgical, radiological importance. Turk Neurosurg. 2011; 21(4): 489-493, indexed in Pubmed: 22194105.

27. Natsis $K$, Piagkou M, Lazaridis $N$, et al. Incidence, number and topography of Wormian bones in Greek adult dry skulls. Folia Morphol. 2019; 78(2): 359-370, doi: 10.5603/ FM.a2018.0078, indexed in Pubmed: 30155873.

28. Nikolova SY, Toneva DH, Yordanov YA, et al. Multiple Wormian bones and their relation with definite pathological conditions in a case of an adult cranium. Anthropol Anz. 2014; 71(3): 169-190, doi: 10.1127/00035548/2014/0355, indexed in Pubmed: 25065115.

29. O'Loughlin VD. Effects of different kinds of cranial deformation on the incidence of wormian bones. Am J Phys Anthropol. 2004; 123(2): 146-155, doi: 10.1002/ ajpa.10304, indexed in Pubmed: 14730648. 
30. Piagkou M, Skotsimara G, Repousi E, et al. Enlarged parietal foramina: a rare finding in a female Greek skull with unusual multiple Wormian bones and a rich parietal vascular network. Anat Sci Int. 2013; 88(3): 175-180, doi: 10.1007/ s12565-013-0173-2, indexed in Pubmed: 23543411.

31. Pryles CV, Khan AJ. Wormian bones. Am J Dis Child. 1979 ; 133(4): 380-382, doi: 10.1001/archpedi.1979.02130040034007, indexed in Pubmed: 433853.

32. Ratnaningrum S. Identification of sutural bones in Indonesian skulls. Transl Res Anat. 2020; 18: 100061, doi: 10.1016/j.tria.2019.100061.

33. Reid TH, Tam A, Antoniou G, et al. Anterior fontanelle Wormian bone with exomphalos major and dysmorphic facial features: a previously unseen association? J Craniofac Surg. 2016; 27(7): 1799-1801, doi: 10.1097/ SCS.0000000000002962, indexed in Pubmed: 27513767.

34. Sanchez-Lara PA, Graham JM, Hing AV, et al. The morphogenesis of wormian bones: a study of craniosynostosis and purposeful cranial deformation. Am J Med Genet A. 2007; 143A(24): 3243-3251, doi: 10.1002/ajmg.a.32073, indexed in Pubmed: 18000970.

35. Saylisoy S. Is there a coexistence of peritemporal wormian bones and congenital aural atresia? J Comput Assist Tomogr. 2020; 44(4): 559-561, doi: 10.1097/ RCT. 0000000000001047 , indexed in Pubmed: 32697526.

36. Semler O, Cheung MS, Glorieux FH, et al. Wormian bones in osteogenesis imperfecta: Correlation to clinical findings and genotype. Am J Med Genet A. 2010; 152A(7): 1681-1687, doi: 10.1002/ajmg.a.33448, indexed in Pubmed: 20583157.

37. Shah $A B$, Tisano BK, Elattar $O$, et al. Foot deformities in hajdu-cheney syndrome: a rare case report and review of the literature. J Orthop Case Rep. 2017; 7(5): 11-15, doi: 10.13107/jocr.2250-0685.876, indexed in Pubmed: 29242787.

38. Sidpra J, Jeelani NU, Ong J, et al. Skull fractures in abusive head trauma: a single centre experience and review of the literature. Childs Nerv Syst. 2021; 37(3): 919-929, doi: 10.1007/s00381-020-04870-6, indexed in Pubmed: 32935234

39. Standring S. Gray's Anatomy E-Book: The Anatomical Basis of Clinical Practice. 42. Elsevier Health Sciences 2020.

40. Teager SJ, Constantine S, Lottering N, et al. Physiologic closure time of the metopic suture in South Australian infants from 3D CT scans. Childs Nerv Syst. 2019; 35(2): 329-335, doi: 10.1007/s00381-018-3957-9, indexed in Pubmed: 30218142.

41. Vinchon M. The metopic suture: Natural history. Neurochirurgie. 2019; 65(5): 239-245, doi: 10.1016/j.neuchi.2019.09.006, indexed in Pubmed: 31562880.

42. Vu HL, Panchal J, Parker EE, et al. The timing of physiologic closure of the metopic suture: a review of 159 patients using reconstructed 3D CT scans of the craniofacial region. J Craniofac Surg. 2001; 12(6): 527-532, doi: 10.1097/00001665-200111000-00005, indexed in Pubmed: 11711818.

43. Walter SD, Eliasziw M, Donner A. Sample size and optimal designs for reliability studies. Stat Med. 1998; 17(1): 101-110, doi: 10.1002/(sici)10970258(19980115)17:1<101::aid-sim727>3.0.co;2-e.

44. Zdilla MJ, Russell ML, Koons AW, et al. Metopism: a study of the persistent metopic suture. J Craniofac Surg. 2018; 29(1): 204-208, doi: 10.1097/SCS.0000000000004030, indexed in Pubmed: 29049140. 